\title{
Treatment of vascular dementia
}

\section{Recommendations of the Scientific Department of Cognitive Neurology and Aging of the Brazilian Academy of Neurology}

\author{
Sonia Maria Dozzi Brucki ${ }^{1,2}$, Ana Cláudia Ferraz², \\ Gabriel R. de Freitas ${ }^{3}$, Ayrton Roberto Massaro ${ }^{4}$, \\ Márcia Radanovic ${ }^{5}$, Rodrigo Rizek Schultz ${ }^{5}$ and \\ Working Group on Alzheimer's Disease and Vascular Dementia \\ of the Brazilian Academy of Neurology
}

\begin{abstract}
Scientific Department of Cognitive Neurology and Aging of ABN had a consensus meeting to write recommendations on treatment of vascular dementia, there was no previous issue. This disease has numerous particularities and can be considered a preventable dementia. Prevention treatment is primary care of vascular risk factors or a secondary prevention of factors that could cause recurrence of ischemic or hemorrhagic brain modifications. In these guidelines we suggested only symptomatic treatment, pharmacologic or nonpharmacologic. We have reviewed current publications on MEDLINE (PubMed), LILACS e Cochrane Library databases. Recommendations are concern to the following factors and their prevention evidences, association, or treatment of vascular dementia: physical activity, tobacco use, diet and food supplements, arterial hypertension, diabetes mellitus, obesity, statins, cardiac failure, atrial fibrillation, antithrombotics, sleep apnea, carotid revascularization, symptomatic pharmacological treatment.
\end{abstract}

Key words: vascular dementia, pharmacological treatment, prevention, cholinesterase.

\begin{abstract}
Tratamento da demência vascular. Recomendações do Departamento Científico de Neurologia Cognitiva e do Envelhecimento da Academia Brasileira de Neurologia

Resumo - O DC de Neurologia Cognitiva e do Envelhecimento da ABN reuniu-se para escrever recomendações para o tratamento da demência vascular, uma vez que não havia nenhuma recomendação neste sentido. Esta doença tem inúmeras particularidades e pode ser considerada uma das demências que pode ser prevenida. O tratamento para sua prevenção é o de cuidados primários para os fatores de risco vasculares, ou a prevenção secundária dos fatores que levam a recorrência de alterações isquêmicas ou hemorrágicas cerebrais. Nestas recomendações sugerimos apenas o tratamento sintomático, medicamentoso ou não. Baseamo-nos nas evidências disponíveis, através da revisão das publicações nas bases MEDLINE (PubMed), LILACS e Cochrane Library. As recomendações dizem respeito aos seguintes fatores e suas evidências na prevenção, associação ou tratamento da demência vascular: atividade física, álcool, tabagismo, dieta e suplementos, hipertensão arterial, diabetes mellitus, obesidade, estatinas, insuficiência cardíaca, fibrilação atrial, antiagregantes, apneia do sono, revascularização carotídea e tratamento farmacológico sintomático.
\end{abstract}

Palavras-chave: demência vascular, tratamento farmacológico, prevenção, inibidores das colinesterases, memantina, diretrizes, consenso, Brasil.

${ }^{1}$ Neurology Service, Hospital Santa Marcelina, Cognitive and Behavioral Neurology Group of Clínicas Hospital of the University of São Paulo School of Medicine (FMUSP), Referral Center for Cognitive Disorders (CEREDIC) of the FMUSP, São Paulo SP, Brazil; ' 2 'Or Or Institute of Research and Teaching, University Federal Fluminense, Rio de Janeiro RJ, Brazil; ${ }^{3}$ Institute of Rehabilitation Lucy Montoro. ${ }^{4}$ Medical Investigation Laboratory 27 (LIM 27 ), Institute of Psychiatry, School of Medicine, University of Sao Paulo, São Paulo SP, Brazil; ${ }^{5}$ Sector of Behavioral Neurology of the Department of Neurology and Neurosurgery of the Federal University of São Paulo (UNIFESP), Center for Brain Aging (NUDEC) - Institute of Memory (UNIFESP), São Paulo SP, Brazil.

Sonia Maria Dozzi Brucki - Rua Rio Grande, 180/61 - 04018-000 São Paulo SP - Brazil. E-mail: sbrucki@uol.com.br

Disclosure: The authors report no conflits of interest.

Received September 15, 2011. Accepted in final form November 20, 2011.

Brucki SMD, et al. Vascular dementia: treatment 
The diagnosis of vascular cognitive impairment (VCI) and vascular dementia (VD) remains controversial. Since a number of criteria are available in the literature, this discussion is of primary importance to Brazil in furthering knowledge, improving diagnosis and gleaning greater understanding of the mechanisms involved in the emergence of cognitive decline due to vascular causes in the Brazilian population.

Thus, VCI has recently been proposed as a term encompassing VD and all other forms of mild to severe cognitive impairment secondary to cerebrovascular disease. The term encompasses three conditions: VCI no dementia, vascular dementia, and $\mathrm{AD}$ with a vascular component. VCI no dementia constitutes the most prevalent VCI subgroup in persons younger than 85 years of age. VD denotes dementia caused by all types of vascular pathology. The current classification of VD includes cortical vascular dementia, subcortical ischemic VD, dementia due to strategic infarct, dementia due to hypoperfusion, and dementia due to hemorrhagic lesions.

Therefore, this subject was extensively addressed and a consensus on its diagnostic criteria by this group can be found in an earlier publication.

Given the array of (often imprecise) criteria used to diagnose VCI and VD among studies on the treatment of vascular risk factors, the task of defining recommendations for treating these diseases, particularly in the prevention of cognitive decline, does not have robust levels of evidence to draw on.

The heterogeneity of the physiopathology, location and magnitude of lesions, diagnostic criteria, and cognitive assessment all vary among studies on cognition, precluding, in the majority of cases, generalization of results for all types of impairment.

\section{Methods}

A search of the electronic PubMed and Scielo databases for articles published up to May 2011 was carried out. Studies containing an abstract that addressed the association among VCI and VD, symptomatic treatment of risk factors for vascular diseases and cognition, or specific treatment of cognition-related symptoms in patients with VCI or VD, were included. Review type articles and metaanalyses on the theme were also included.

The themes chosen were divided by members of the consensus group into: physical activity; diet and food supplementation; alcohol, obesity, smoking, treatment of arterial hypertension, diabetes, dyslipidemia, cardiac insufficiency, atrial fibrillation;sleep apnea and antiaggregants. Regarding specific symptomatic treatment, trials with cholinesterase inhibitors and glutamate antagonist, cytocholine, calcium channel blockers, cerebrolysin and pentoxifylline were assessed.

After selection of articles, these were classified into Classes I, II and III, while recommendations were qualified according to levels of evidence with A, B, C and $\mathrm{U}$ ratings. The criteria employed are summarized in Tables 1 and 2, and were based on the recommendations of the American Academy of Neurology published in 2008.

\section{Physical activity}

Animal studies have shown that physical activity stimulates angiogenesis, synaptogenesis and neurogenesis. Rats subjected to treadmill running had more astrocytes and neuroblasts able to proliferate in the subgranular zone of the dentate gyrus of the hippocampus, as well as a greater number of neurons in the transient stage, compared to control animals. ${ }^{1}$

Physical exercise also reduces risk factors for vascular diseases and can release hormonal factors which enhance neuronal functioning, lending support to the theory of potential benefits. Such benefits have also been confirmed in clinical trials.

In a recent 8-year follow-up study involving 3075 elderly between 70 and 79 years of age in 1997, 30\% of the group presented cognitive decline at the end of the followup period. Multivariate analysis of the initial variables associated good evolution with younger age, white ethnicity, higher level of education and literacy, moderate to vigorous exercise, and non-smoking status. ${ }^{2}$

Some evidence indicates that physical activity plays a role in preventing dementia and conversion from mild cognitive impairment (MCI) to dementia in the form of Alzheimer's disease (AD) or $\mathrm{VD}^{3-6} \mathrm{~A}$ recent meta-analysis of prospective studies involving 33816 non-demented individuals at base line, followed up for one to 12 years, found that a high level of physical activity was associated to a $38 \%$ reduction in risk of cognitive decline, whereas light to moderate physical activity was also associated to a $35 \%$ reduction in risk of decline. ${ }^{7}$

In the randomized clinical trial by Lautenschlager et al., physical activity was associated to lower risk of developing MCI and dementia among adults with subjective memory complaints. ${ }^{3}$ Volunteers were 50 years of age or older and randomly assigned to an educational program or to a domiciliary physical exercise program lasting a period of 24 weeks. A statistically significant difference, albeit modest, was seen in the cognitive performance of the group that performed the physical activity, a difference which persisted after an 18 -month period. ${ }^{3}$

Studies in the literature show a statistically significant benefit from physical activity. However, preventive effects 
Table 1. Classification of studies.

Class I. A randomized, controlled clinical trial of the intervention of interest with masked or objective outcome assessment, in a representative population. Relevant baseline characteristics are presented and substantially equivalent among treatment groups or there is appropriate statistical adjustment for differences.

The following are also required:

a. Primary outcome(s) clearly defined.

b. Concealed allocation clearly defined.

c. Exclusion/inclusion criteria clearly defined.

d. Adequate accounting for drop-outs (with at least $80 \%$ of enrolled subjects completing the study) and cross-overs with numbers sufficiently low to have minimal potential for bias.

e. For non-inferiority or equivalence trials claiming to prove efficacy for one or both drugs, the following are also required ${ }^{*}$ :

1. The standard treatment used in the study is substantially similar to that used in previous studies establishing efficacy of the standard treatment. (e.g. for a drug, the mode of administration, dose and dosage adjustments are similar to those previously shown to be effective).

2. The inclusion and exclusion criteria for patient selection and the outcomes of patients on the standard treatment are comparable to those of previous studies establishing efficacy of the standard treatment.

3. The interpretation of the results of the study is based upon an analysis of cases observed.

Class II. A randomized controlled clinical trial of the intervention of interest in a representative population with masked or objective outcome assessment that lacks one criteria a-e above or a prospective matched cohort study with masked or objective outcome assessment in a representative population that meets b-e above. Relevant baseline characteristics are presented and substantially equivalent among treatment groups or there is appropriate statistical adjustment for differences.

Class III. All other trials (including well-defined natural history controls or patients serving as own controls) in a representative population, where outcome is independently assessed, or independently derived by objective outcome measurement.

Class IV. Studies not meeting Class I, II or III criteria including consensus or expert opinion.

${ }^{*}$ Note that numbers 1-3 in Class Ie are required for Class II in equivalence trials. If any one of the three are missing, the class is automatically downgraded to Class III.

Table 2. Levels of evidence.

A. Established as effective, ineffective or harmful (or established as useful/predictive or not useful/predictive) for the given condition in the specified population (Level A rating requires at least two consistent Class I studies)*.

B. Probably effective, ineffective or harmful (or probably useful/predictive or not useful/predictive) for the given condition in the specified population (Level B rating requires at least one Class I study or two consistent Class II studies).

C. Possibly effective, ineffective or harmful (or possibly useful/predictive or not useful/predictive) for the given condition in the specified population (Level C rating requires at least one Class II study or two consistent Class III studies).

U. Data inadequate or conflicting;given current knowledge, treatment (test, predictor) is unproven.

${ }^{*}$ In exceptional cases, one convincing Class I study may suffice for an "A" recommendation if 1) all criteria are met, 2) the magnitude of effect is large (relative rate improved outcome $>5$ and the lower limit of the confidence interval is $>2$ ).

seem to be weaker in VD than $\mathrm{AD} .^{8}$ Studies investigating cognitive performance and physical activity have tended to involve a smaller number of VD patients, yet all showed a reduced risk of dementia..$^{9,10}$

In post-stroke patients, there is an increased risk for reduced physical activity, predominantly among those with cognitive impairment, especially executive function disorders. ${ }^{11}$

A meta-analysis revealed lower VD in patients that per- formed physical activity (odds ratio $0.62-\mathrm{CI}$ : 0.42-0.92). ${ }^{12}$ In an observational study in community-dwelling elderly, physical activity proved preventive for the development of VCI in women. ${ }^{13}$ An Italian prospective study assessing the efficacy of physical activity in reducing the risk of developing $\mathrm{AD}$ or $\mathrm{VD}$ in elderly individuals found physical activity to be associated to a lower risk of $\mathrm{VD}$, but not of AD. ${ }^{14} \mathrm{~A}$ prospective long-term (up to 21 years) follow-up study of 401 community-dwelling older adults, found that taking 
part in cognitive activities, but not in physical activities, was associated to a lower risk of VCI with or without dementia. ${ }^{15}$

Several controlled trials are underway assessing the effect of physical activity on patients with VCI and AD. ${ }^{16,17}$

Recommendations - Regular physical activity should be recommended to healthy individuals, patients with cerebrovascular disease, and to patients with cognitive decline (Level of evidence B)

\section{Diet and supplements}

A balanced diet, specifically a Mediterranean diet characterized by high consumption of fruit, vegetables, legumes, grains and unsaturated fatty acids (olive oil);low intake of milk and milk-derived products, meat and saturated fatty acids plus moderate consumption of alcohol, have been associated to a lower risk for dementia as well as reduced conversion of MCI to AD. ${ }^{18-20}$ The vascular factors can be linked to a Mediterranean diet, but other nonvascular biological mechanisms (oxidative and inflammatory) may be responsible for explaining the complex epidemiological association between a Mediterranean diet and cognitive decline. ${ }^{21}$

In a population-based cohort study, high adherence to a Mediterranean diet was associated, during follow up, with lower decline in scores on the Mini-Mental State Exam, although this did not translate to a similarly reduced risk for dementia. Differences can occur depending on the study venue and on previous diet, whereby the cited study was run in France, whilst the others were done in North America. ${ }^{22}$

Randomized trials have failed to show any effect of food supplementation with various substances on cognitive decline prevention. Substances supplemented have included omega $3 ;^{23,24}$ vitamin C, E and beta carotene, ${ }^{25}$ vitamin $\mathrm{B} 12$, folic acid and vitamin $\mathrm{B} 6{ }^{26}$

Recommendations - Adapting the diet and effecting changes in eating habits are important by promoting consumption of healthy foods predominantly vegetables, unsaturated fatty acids, grains and fish (Level of evidence B).

\section{Alcohol}

The majority of studies on alcohol and cognition have shown that consumption of low amounts of alcohol has a preventive effect on the development of $\mathrm{VD}, \mathrm{AD}$ and other types of dementia. ${ }^{27}$

There is compelling evidence that consumption of alcohol in moderation is associated to a lower risk of coronary diseases, ischemic strokes and dementia. The underlying protective mechanisms involved include reduced LDL and increased HDL; decreased resistance to insulin; lowering of blood pressure; reduced platelet aggregation and fibrinogen levels and lower serum homocysteine and inflammatory markers. In addition, anti-amyloidogenic activity promoted by resveratrol (present in red wine) also seems to occur. ${ }^{28-35}$

Although studies show a positive correlation between alcohol consumption and dementia prevention, with some benefit associated to wine consumption, there is a deleterious effect of alcohol when consumed at high doses. The consumption of two daily drinks $(<30 \mathrm{~g} / \mathrm{d})$ is associated with reduced overall risk, whereas three or more drinks is associated to increased risk of ischemic or hemorrhagic stroke (CVA). ${ }^{36}$

Recommendations - The consumption of high doses of alcohol must be avoided (Level of evidence C).

\section{Obesity}

Dementia risk is higher among overweight and obese individuals..$^{2-37}$ There is a positive association between body mass index in adult life and emergence of $\mathrm{AD}$ and VD in later life. with a five-fold higher risk of VD in obese subjects and twice the risk among overweight individuals, independently of vascular factors. ${ }^{38}$

Recommendations - Keeping weight within normal levels should be encouraged (Level of evidence C).

\section{Systemic arterial hypertension}

Systemic arterial hypertension (SAH) is a potential risk factor for cognitive impairment and dementia, including the vascular type ${ }^{39} \mathrm{~A}$ class-specific effect of anti-hypertensive drugs toward reducing cognitive impairment has been postulated in some studies. However, the cognitive outcomes of these studies was not considered the primary outcomes, while investigations involved heterogeneous populations with no standardization of tests or diagnostic criteria for defining cognitive decline or dementia, including its subtypes. In addition, these assessments were not adapted for target populations with socioeconomic and cultural disparities, while no supplementary methods such as imaging techniques were used to help corroborate outcomes.

The HYVET trial (Hypertension in the very elderly Trial) was a double-blind controlled trial using indapamide and perindopril in older elderly over 80 years of age which was cut short due to the benefits of using anti-hypertensives for reducing mortality and strokes. The HYVET-COG substudy showed a non-significant reduction in dementia in the treated sub-group..$^{40}$ 
Recommendations - The use of anti-hypertensives can reduce the risk of cognitive decline and dementia, including VD. Currently, there is insufficient evidence to recommend the use a specific class of anti-hypertensives (Level of evidence B).

\section{Statins}

Dyslipidemic individuals have an elevated risk for developing dementia. Moreover, observational studies have shown that individuals treated with statins have lower risk for dementia. The preventive effect of statins in dementia hinges on their hypolipidemic effect. In addition, they exert anti-platelet, anti-thrombotic, anti-inflammatory effects and also have an impact on the formation of the beta amyloid protein, favoring the non-amyloidogenic path by alpha secretase.

Two randomized trials (HPS2002 and PROSPER2002) which included 26340 patients aged older than 70 years followed up for between 5 and 3.2 years, respectively, failed to confirm any effect on the incidence of dementia or cognitive decline. The HPS study using simvastatin, and the PROSPER with pravastatin, both found a significant reduction in LDL levels. ${ }^{41}$

The LEADe study was a randomized, double-blind, multi-center trial in 640 patients with mild to moderate $\mathrm{AD}$ assigned to receive atorvastatin $80 \mathrm{mg} /$ day or placebo for 72 weeks. Results revealed no benefit in the treated group over placebo on cognition measured by the ADASCog or on global functioning as measured by the ADCSCGIC. No studies have assessed the role of statins in the management of VD. ${ }^{42}$

Recommendations - The use of statins in elderly individuals, subjects with vascular risk factors, is not recommended exclusively for the prevention or treatment of dementia (Level of evidence B).

\section{Diabetes}

Recent studies have shown that diabetes is a risk factor for the manifestation of AD and VD. Besides raising the risk of vascular diseases, resistance to insulin has direct neuronal effects owing to glucose-induced toxicity (oxidative stress), abnormalities in homeostasis of cerebral insulin (amyloid metabolism) and microvascular abnormalities.

The occurrence of severe hypoglycemia in patients with type $2 \mathrm{DM}$ can be associated to an increased risk of dementia, which rises with the number of hyperglycemic

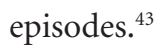

The ACCORD-MIND trial was designed to assess whether strict control of glycemia (target glycated hemoglobin lower than 6\%) offers benefits over conventional levels (7 to $7.9 \%$ ) for preventing cognitive decline. ${ }^{44}$ However, the ACCORD study showed that strict control of glycemia increased mortality and is contra-indicated in diabetic patients at high risk. ${ }^{45}$

Studies using PPAR-gamma (pioglitazone and rosiglitazone), independently of the presence of DM or glucose intolerance, have shown positive effects on cognition in AD. However, the study with rosiglitazone was discontinued as a result of increased mortality from cardiac problems in the treated group.

Recommendations - Strict control of glycemia (Glycated $\mathrm{Hb}<6 \%$ ) is not recommended for exclusively preventing cognitive decline in diabetic patients (Level of evidence B).

\section{Cardiac failure}

Patients with low cardiac output have poor results on neuropsychological assessment, particularly regarding executive functions. In the Framingham trial, cardiac output was found to be associated to brain volume, where reduced cardiac function was related to faster brain aging, independently of vascular risk factors. ${ }^{46}$ Thus, if a reduction in systemic blood flow directly affects cerebral blood flow, then consequently, low cardiac output will reduce cerebral blood flow and contribute to encephalic compromise. ${ }^{47,48}$

The few studies available suggest that ACE inhibitors can have a beneficial effect on cerebral perfusion. In two such studies, patients with systolic dysfunction of the left ventricle (functional class NYHA III and IV) were treated with captopril ${ }^{49,50}$ leading to improved cerebral blood flow.

The use of ACE inhibitors has been associated to cognitive improvement, independently of basal blood pressure levels..$^{51} \mathrm{~A}$ study assessing the impact of the use of antihypertensive drugs on cognition and cerebral vasoreactivity is currently underway. ${ }^{52}$

Recommendations - The treatment of potentially modifiable co-morbidities associated to cardiac failure in elderly patients (anemia, SAH, electrolyte abnormalities, hyperglycemia, hypoalbuminemia) can attenuate cognitive decline in this patient group (Level of evidence C). The use of ACE inhibitors can be recommended in patients with cardiac failure, independently of treatment to control blood pressure (Level of evidence C).

\section{Atrial fibrillation}

Atrial fibrillation is a consistent risk for dementia in patients with history of cerebrovascular events, but this association is less clear in the broader AF patient popula- 
tion. ${ }^{53}$ Elderly patients with cognitive decline had shorter periods within the therapeutic window. ${ }^{54}$

Recommendations - In patients with AF and cognitive decline special attention should be paid to ensure adequate anticoagulation control (Level of evidence $\mathrm{C}$ ).

\section{Sleep apnea}

Studies have associated sleep apnea to cognitive decline in elderly without dementia (mildly affected) and also in more severe cases of apnea. Treatment of this sleep disturbance has a limited impact on cognition, and requires further exploration.

Sleep disturbance and day time sleepiness are risk factors for VD. ${ }^{55}$ Treatment of obstructive sleep apnea in $\mathrm{AD}$ patients has proven effective for improving some aspects of cognition and the quality of sleep in randomized studies. ${ }^{56}$

Recommendations - Obstructive sleep apnea must be investigated and treated in patients with dementia, and can yield some cognitive benefits (Level of evidence C).

\section{Tobacco use}

Smokers are at greater risk of developing dementia in general, and more specifically, AD and VD. This finding has repeated in a number of observational studies. ${ }^{57,58}$ In the 23-year follow-up study by Rusanen et al. comparing 5367 individuals split into smokers of more than two packs a day and into non-smokers, showed the former group to be at higher risk for dementia (HR, 2.14;95\% CI, 1.65-2.78), for $\mathrm{AD}$ (HR, 2.57;95\% CI, 1.63-4.03), and for VD (HR, $2.72 ; 95 \%$ CI, 1.20-6.18). ${ }^{59}$

The mechanisms involved include increased oxidative stress, greater inflammatory response, increase in the number of amyloid plaques and atherosclerosis. No controlled studies evaluating the impact of stopping smoking on cognition in later life have been published. Further studies are needed to determine at which point stopping smoking can lead to reduced risk. ${ }^{36}$

Recommendations - Stopping smoking should be recommended at any stage of life (Level of evidence C).

\section{Antiaggregants}

In $\mathrm{AD}$ patients, the administration of acetylsalicylic acid increased the risk of hemorrhaging and led to no benefits in cognition. These patients should be given aspirin for vascular improvement. ${ }^{60,61}$

Regarding the prevention of dementias ( $\mathrm{AD}$ and $\mathrm{VD}$ ), epidemiological indices show that the use of non-hormon- al anti-inflammatory drugs and acetylsalicylic acid reduces the risk of dementia. ${ }^{62,63}$

A randomized trial of aspirin and placebo spanning five years in individuals older than 50 years found no significant difference in cognition. ${ }^{64}$ The PROFESS study assessed acetylsalicylic acid plus dipyridamole versus clopidogrel and telmisartan, showing no difference between the impact of the two antiaggregants on cognition assessed by the Mini-Mental State Exam. ${ }^{65}$

Recommendations - The use of antiaggregants for primary prevention of cognitive decline and dementia is not recommended (Level of evidence B). The administration of acetylsalicylic acid is not indicated in $\mathrm{AD}$ patients for treating dementia, except when indicated for cardiovascular reasons (Level of evidence B).

\section{Carotid revascularization}

Carotid revascularization in patients with symptomatic carotid stenosis has been proven to reduce risk of stroke recurrence and is considered an effective approach to secondary prevention in patients with large artery occlusive disease. However, the impact of carotid revascularization on cognitive performance remains controversial.

Numerous studies have assessed cognitive function after carotid revascularization either by surgical approach, carotid endarterectomy (CEA) or endovascular by carotid artery stenting (CAS) . The outcomes reported by these studies have been conflicting. Many studies have shown no changes in cognition after the procedure, some have noted improvements while others have found decline. ${ }^{66-70}$

The likely reasons behind this disparity in results include differences in method and in the variables associated to patients. Notable methodological difference were types of tests employed, timing of test performance, and presence or otherwise of a control group. Patient-related variables included age and frequency of comorbidities (diabetes, previous stroke).

The majority of studies involved only a small number of patients. In addition, none of the studies estimated the power of the study a priori. These limitations may have led to results with low power for detecting differences in the outcomes assessed.

Only half of the studies assessing cognitive performance pre and post carotid revascularization were controlled. Of those studies incorporating a control group, the profile of the group was non-uniform with the inclusion of healthy individuals as well as cases of peripheral vascular surgery, orthopedic surgery, laminectomy, post angiography, among other conditions.

All the limitations outlined above mean the results 
of these studies must be interpreted with caution. Earlier reviews including studies published up to the year 2000, have suggested improvement in cognitive outcome after $\mathrm{CEA},{ }^{70,71}$ whereas a recent systematic review of trials with CEA and CAS, all published after 1990, showed that neither of the two procedures affected cognition. ${ }^{72}$

This latter review included 32 studies and analyzed results of tests assessing three cognitive domains: memory, executive function and language. However, no studies explored global assessment and dementia scores. Due to the heterogeneity of the methods used in different studies, the data from this review could not be pooled into a metaanalysis. According to the results of the review, carotid revascularization has no effect on cognitive performance in patients that did not have a stroke after the procedure. ${ }^{72}$

Three studies compared cognitive performance in patients treated with CEA versus angioplasty/CAS in substudies of two large clinical trials (CAVATAS and SPACE). None of these studies found any difference in cognition between the two groups (CEA versus Angioplasty/CAS). ${ }^{73,74}$

Data on the two procedures indicated for carotid revascularization will now be described, namely, CEA and CAS.

\section{COGNITION AFTER CAROTID ENDARTERECTOMY (CEA)}

Studies comparing cognitive performance before and after CEA have reported conflicting results. While the majority found no difference in pre and post procedure assessments, some studies showed deterioration while others reported improvement. Moreover, there was a lack of consistency in results on the different tests. ${ }^{72}$

Cognitive assessment after CEA was performed very early which may have led to underestimation of potential differences. Some studies have suggested that the potential effect of treatment on cognition tended to be more evident in assessments conducted later. Only one study had a follow-up period exceeding 1 year. This study showed cognitive decline over 3 years, evidenced by poorer scores on the mini mental state exam and worsening of motor abilities. ${ }^{72}$

\section{COGNITION AFTER CAROTID ARTERY STENTING (CAS)}

Studies assessing neuropsychological performance pre and post CAS also reported conflicting results. Half of the studies observed improvements in verbal memory. However, no difference in the language domain was detected, a domain which is harder to investigate in these patients. A potential effect of laterality has been proposed in several studies. ${ }^{66,69}$

The vast majority of the studies had extremely short follow-up periods. No data on patients' cognitive performance is available 6 months after undergoing the CAS.

The use of a protective device against embolisms can produce benefits in terms of cognition. Studies with CAS and no protective device (earlier studies) have found no changes in cognitive performance pre and post procedure. However, recent studies that more frequently used brain protection devices against embolism have shown cognitive improvement. ${ }^{68,75}$

A higher frequency of microembolism was noted in patients treated with CAS compared to those submitted to CEA. Nevertheless, no correlation between microembolism (detected by transcranial Doppler) and poorer cognitive outcome was evident.

Recommendations - Carotid revascularization using CEA or CAS in patients with symptomatic carotid stenosis has no effect on cognitive performance. Carotid revascularization should not be recommended for the purpose of preserving or improving cognitive function (Level C).

\section{Symptomatic pharmacological therapy}

The measures listed below are exclusively intended for the management of VD cases, with approaches for $\mathrm{AD}$ treatment published in a separate article of the journal.

Currently, there is no Class I evidence to recommend specific symptomatic treatment for VD. A reduction in acetylcholine and choline acetyltransferase occurs in this dementia type, particularly in the presence of deep lesions, consequently impairing cholinergic pathways. Clinical trials using drugs with diverse mechanisms of action such as vasodilator effect, free-radical reducers, promoters of increased cerebral metabolism (through elevated glucose and oxygen extraction), with hemorheological properties, although based on justifiable theoretical presumptions given the physiopathological mechanism underlying VD, have failed to show efficacy in clinical practice. Potential beneficial effects can be attributed to inhibitors of cholinesterase.

No consistent benefits have been found for the treatment of VD in randomized trials based on the following drugs:

\section{GINKGO BILOBA}

All studies on this medication have involved dementia of various causes with no investigations dedicated to $\mathrm{VD}$ alone. Studies including a VD subgroup have adopted heterogeneous diagnostic criteria and produced inconsistent results. $^{76}$

\section{NICERGOLINE}

No studies using this drugs focusing specifically on VD have been conducted. In those studies including a subgroup for this form of dementia, the criteria used for its 
diagnosis were poorly defined. All studies eligible for the Cochrane review consulted for this subject were early, having been published up to 1999. The results of these studies are inconclusive. ${ }^{77}$

\section{VINPOCETINE}

The few studies with a suitable methodology using this medication are early (published up to 1991) and include various forms of dementia, with heterogeneous diagnostic criteria. There is no evidence to justify the clinical use of this drug for the treatment of VD. ${ }^{78}$

\section{CO-DERGOCRINE MESYLATE (HYDERGINE)}

\section{AND OTHER ERGOLOID MESYLATES}

only two methodologically sound trials on the use of co-dergocrine in VD are available. The results are inconclusive given the impossibility of comparing outcomes obtained by the two studies and owing to the small number of patients assessed. ${ }^{79}$

\section{PIRACETAM}

No clinical trials specifically designed for VD are available and the diagnostic criteria for the various forms of dementia in the studies assessed were highly heterogeneous. Therefore, based on current evidence, it can be concluded that this medication should not be used for the treatment of VD. ${ }^{80}$

Recommendations - The medications above should not be used in the treatment of VD (Level of evidence B).

\section{PENTOXIFYLLINE}

This agent is derived from xanthine which improves blood flow by increasing the deformability of erythrocytes through phosphodiesterase inhibition. A systematic review published in 2003 evidenced only four methodologically eligible clinical trials for assessment which used pentoxifylline for VD. The authors concluded that despite holding potential for inclusion in future studies (two studies showed performance improvement on some domains of the cognitive assessment in the pentoxifylline-treated group), the quality of the trials published to date cannot support its clinical use. ${ }^{81}$

Recommendations - Pentoxifylline is not recommended for the treatment of VD (Level of evidence U).

\section{CITICOLINE}

The mechanism of action of the drug Citicoline (Cytidinephosphocholine - CDP-choline) is unclear but it is believed to exert a repairing action through resynthesis of phospholipids after lesion and may act in cholinergic deficit.
A meta-analysis by the Cochrane group including seven articles showed some effect on memory, behavior and clinical global impression. However, the studies were heterogeneous in terms of doses used (ranging from 100 to $1000 \mathrm{mg} /$ day), form of administration, inclusion criteria of subjects and outcome measures. Data published to date points to the need for randomized studies with a larger number of patients and longer follow-up periods. ${ }^{82}$

Recommendations - Currently available data is insufficient to be able to recommend citicoline for the prevention or management of patients with VD (Level C).

\section{CEREBROLYSIN}

This consists of a peptidergic compound with neurotrophic activity administered via the endovenous route. To date, a total of three randomized, double-blind clinical trials have been published using cerebrolysin. The study with the largest number of participants ( 242 individuals), ${ }^{83}$ showed a significant difference compared to placebo on scales measuring cognition (ADAS-Cog) and clinical impression (CIBIC+) (Class II). Studies involving larger cohorts are needed to confirm these observations.

Recommendations - Cerebrolysin is not recommended for the treatment of VD (Level of evidence C).

\section{Cholinesterase inhibitors and glutamate receptor antagonists}

A meta-analysis study assessing cholinesterase inhibitors and memantine found a positive effect on the ADASCog for all these medications ranging from a decrease of 1.10 for rivastigmine to -2.17 for donepezil. Only donepezil had an influence on the global clinical assessment measure. None of the drugs produced any behavioral or functional adverse effects except for donepezil at a dose of $10 \mathrm{mg} / \mathrm{d}$. Benefits on cognition were small and of questionable clinical significance. ${ }^{84}$ Further studies are needed and their accuracy shall depend on the etiological mechanism implicated in VCI and the separation among its subtypes.

\section{DONEPEZIL}

This proved well tolerated and was shown to improve cognitive symptoms and functional abilities in VCI patients. Further, more extensive studies are required that assess the safety and efficacy of the drug for promoting the delay of cognitive decline. ${ }^{85-89}$

\section{RIVASTIGMINE}

Rivastigmine exerts specific activity in brain regions associated with executive dysfunction and reduced attention. 
Thus, there are theoretical grounds for believing that rivastigmine can be beneficial for treating VCI but no doubleblind, placebo-controlled clinical trials are available.

\section{GALANTAMINE}

This drug is known to have limited efficacy in treating dementia secondary to vascular lesion. In mixed dementia (vascular lesions and $\mathrm{AD}$ ), some evidence points to benefits for cognition..$^{95-100}$

Recommendations - Current data is lacking to be able to justify the use of these substances in VD treatment. Assessments of VD sub-types are needed and use should be dedicated and targeted (Level of Evidence B). Benefits seem more marked in subcortical VD patient, according to the opinion of specialists involved in this consensus (Level of evidence C).

\section{MEMANTINE}

Memantine is a glutamate receptor antagonist (NMDA) which acts as a neuroprotective agent in dementia by blocking the neurotoxic activity of glutamate. The Cochrane review on the use of this medication in dementia incorporates only two clinical trials in patients solely with $\mathrm{VD}$, while three trials included patients with $\mathrm{AD}$ and VD. ${ }^{101}$ Although results of the trials in VD patients showed slight improvement on ADAS-Cog scores, this did not reflect in improved cognitive performance from a clinical standpoint. Mobius et al. suggested that memantine can be more effective in patients with subcortical VD, explaining the low clinical repercussion in studies that encompassed various forms of VD. ${ }^{101}$ This hypothesis has yet to be confirmed by specific studies in well-defined groups with subcortical VD.

Recommendations - The data available is insufficient to justify the use of these substances in VD. Assessments of VD sub-types are needed and use should be dedicated and targeted (Level of Evidence B). Benefits seem more marked in subcortical VD patients, according to the opinion of specialists involved in the consensus (Level of evidence C).

\section{Calcium channel blockers}

Two drugs of this class were tested for VD, namely, nimodipine and nicardipine.

A meta-analysis of 10 trials assessing the efficacy of nimodipine in randomized, double-blind, clinical trials of short duration (12 weeks) revealed global clinical improvement in nimodipine-treated patients. In randomized, double-blind, placebo-controlled trial, Pantoni et al. affirmed that patients with subcortical VD in use of nimodipine for 12 months had less marked decline on the MMSE and GDS compared with subjects given placebo. ${ }^{103} \mathrm{~A}$ persistent beneficial effect from use of nimodipine has yet to be satisfactorily demonstrated by long-term studies (longer than 12 weeks), weakening the arguments for its introduction in routine clinical practice. ${ }^{104}$

Two trials have been conducted on use of nicardipine in VD, both with methodological limitations which preclude the validation of the results. In the study conducted by the Spanish Group of Nicardipine Study in Vascular Dementia, favorable results were found for women only, as well as in patients concomitantly using platelet antiaggregants (Class II). ${ }^{105}$ The study by Gonzalez-Gonzalez and Lorano encompassing 5000 patients, showed improvement after six months of nicardipine use only among a sub-set of patients that presented with more severe condition at study baseline (Class III). ${ }^{106}$

Recommendations - Neither nimodipine nor nicardipine can be recommended for the treatment of VD (Level of evidence C).

\section{References}

1. Uda M, Ishido M, Kami K, Musuhara M. Effects of chronic treadmill running on neurogenesis in the dentate gyrus of the hippocampus of adult rat. Brain Res 2006;1104:64-72.

2. Yaffe K, Fiocco AJ, Vittinghoff E, et al. Predictors of maintaining cognitive function in older adults. The Health ABC Study Neurology 2009;72:2029-2035.

3. Lautenschlager NT, Cox KL, Flicker L, et al. Effect of physical activity on cognitive function in older adults at risk for Alzheimer's disease. A randomized trial. JAMA 2008; 300:1027-1037.

4. Weuve J, Kang JH, Manson JE, Breteler MM, Ware JH, Grodstein F. Physical activity, including walking, and cognitive function in older women. JAMA 2004;292:1454-1461.

5. Larson EB, Wang L, Bowen JD, et al. Exercise is associated with reduced risk for incidente dementia among persons 65 years of age and older. Ann Intern Med 2006;144:73-81.

6. Etgen T, Sander D, Huntgeburth U, et al. Physical activity and incident cognitive impairment in elderly persons: The INVADE study. Arch Intern Med 2010;170:186-193.

7. Sofi F, Valecchi D, Bacci D, et al. Physical activity and risk of cognitive decline: a meta-analysis of prospective studies. J Intern Med 2011;269:107-117.

8. Rockwood K, Middleton L. Physical activity and the maintenance of cognitive function. Alzh Dementia 2007;3:S38-S44.

9. Laurin D, Verreault R, Lindsay J, MacPherson K, Rockwood K. Physical activity and risk of cognitive impairment and dementia in elderly persons. Arch Neurol 2001;58:498-504.

10. Abbott RD, White LR, Ross GW, et al. Walking and dementia in physically capable elderly men. JAMA 2004;292:14471453.

11. Pahlman U, Savborg M, Tarkowski E. Cognitive dysfunction and physical activity after stroke: The Gothenburg Cognitive Stroke Study in the Elderly. J Stroke Cerebrovasc Dis 2011; epub ahead of print. 
12. Aarsland D, Sardahee FS, Anderssen S, Ballard C, the Alzheimer's Society Systematic Review Group. Aging Ment Health 2011;14: 386-395.

13. Middleton L, Kirkland S, Rockwood K. Prevention of CIND by physical activity: different impact on VCI-ND compared with MCI. J Neurol Sci 2008;269:80-84.

14. Ravaglia G, Forti P, Lucicesare A, et al. Physical activity and dementia risk in the elderly: findings from a prospective Italian study. Neurology 2008;70:1786-1794.

15. Verghese J, Wang C, Katz MJ, Sanders A, Lipton RB. Leisure activities and risk of vascular cognitive impairment in older adults. J Geriatr Psychiatry Neurol 2009;22:110-118.

16. Liu-Ambrose T, Eng JJ, Boyd LA, et al. Promotion of the mind through exercise (PROMoTE): a proof of concept randomized controlled trial of aerobic exercise training in older adults with vascular cognitive impairment. BMC Neurology 2010;10:14.

17. Cyarto EV, Cox KL, Almeida OP, et al. The fitness for the ageing brain study II (FABS II): protocol for a randomized controlled clinical trial evaluating the effect of physical activity on cognitive function in patients with Alzheimer's disease. Trials 2010;11:120.

18. Scarmeas N, Stern Y, Mayeux R, Luchsinger JA. Mediterranean diet, Alzheimer disease, and vascular mediation. Arch Neurol 2006;63:739-747.

19. Scarmeas N, Stern Y, Tang MX, Mayeux R, Luchsinger JA. Mediterranean diet and risk for Alzheimer's disease. Ann Neurol 2006;59:922-927.

20. Scarmeas N, Sterm Y, Mayeux R, Manly JJ, Schupf N, Luchsinger JA. Mediterranean diet and Mild Cognitive Impairment. Arch Neurol 2009;66:216-225.

21. Frisardi V, Panza F, Seripa D, et al. Nutraceutical properties of Mediterranean diet and cognitive decline: possible underlying mechanisms. J Alzheimers Dis 2010;22:715-740.

22. Féart C, Samieri C, Rondeau V, et al. Adherence to a mediterranean diet, cognitive decline, and risk of dementia. JAMA 2009; 302:638-648.

23. Van de Rest O, Geleijnse JM, Kok FJ, et al. Effect of fish oil on cognitive performance in older subjects: a randomized, controlled trial. Neurology 2008;71:430-438.

24. Cole GM, Frautschy. DHA may prevent age-related dementia. J Nutrition 2010;140:869-874.

25. Kang JH, Cook NR, Manson JE, et al. Vitamin E, Vitamin C, Beta Carotene, and cognitive function among women with or at risk of cardiovascular disease: the women antioxidant and cardiovascular study. Circulation 2009;119:2772-2780.

26. Kang JH, Cook N, Manson J et al. A trial of B vitamins and cognitive function among women at high risk of cardiovascular disease. Am J Clin Nutr 2008;88:1602-1610.

27. Anstey KJ, Holly MA, Cherbuin N. Alcohol consumption as a risk factor for dementia and cognitive decline: meta-analysis of prospective studies. Am J Geriatr Psychiatr 2009; 17:542-555.

28. Ruitenberg A, van Sweiten JC, Witteman JCM, et al. Alcohol consumption and risk of dementia: the Rotterdam study. Lancet 2002;359:281-286.

29. Mukamal KJ, Kuller LH, Fitzpatrick AL, et al. Prospective study of alcohol consumption and risk of dementia in older adults. JAMA 2003;289:1405-1413.

30. Espeland MA, Gu L, Masaki KH, et al. Association between repor- ted alcohol intake and cognition: results from the Women's Health Initiative Memory Study. Am J Epidemiol 2005;161:228-238.

31. Collins MA, Neafsey EJ, Mukamal KJ, et al. Alcohol in moderation, cardioprotection, and neuroprotection: epidemiological considerations and mechanistic studies. Alcohol Clin Exp Res 2009:33:206-219.

32. Mehlig K, Skoog I, Guo X, et al. Alcoholic beverages and incidence of dementia: 34-year follow-up of the prospective population study of women in Göteborg. Am J Epidemiol 2008; 167:684-691.

33. Marambaud P, Zhao H, Davies P. Resveratrol promotes clearance of Alzheimer's disease amyloid- $\beta$ peptides. J Biol Chem 2005;280:37377-37382.

34. Vingtdeux V, Dreses-Werringloer U, Zhao H, Davies P, Marambaud P. Therapeutic potential of resveratrol in Alzheimer's disease. BMC Neuroscience 2008;9(Suppl 2):S6.

35. Brucki SMD. Does prevention for Alzheimer's disease exist? Dement Neuropsychol 2009;3:209-213.

36. Hughes TF, Ganguli M. Modifiable midlife risk factors for latelife cognitive impairment and dementia. Curr Psychiatr Rev 2009;5:73-92.

37. Sturman MT, Mendes de Leon CF, Bienias JL, et al. Body mass índex and cognitive decline in a biracial community population. Neurology 2008;70:360-367.

38. Whitmer RA, Gunderson EP, Quesenberry Jr CP, Zhou J, Yaffe K. Body mass index in midlife and risk of Alzheimer disease and vascular dementia. Curr Alzheimer Res 2007; 4:103-109.

39. Sharp SI, Aarsland D, Day S et al. Hypertension is a potential risk factor for vascular dementia: systematic review. Int J Geriatr Psychiatr 2011;26:661-669.

40. Peters R, Beckett N, Forette F ET AL. Incident dementia and blood pressure lowering in the Hypertension in the Very Elderly Trial cognitive function assessment (HYVET-COG): a doubleblind, placebo controlled trial. Lancet Neurol 2008; 7:683-689.

41. McGuiness B, Craig D, Bullock R, Passmore P. Statins for the prevention of dementia. Cochrane Database Syst Rev 2009; 15:CD003160.

42. McGuiness B, OHare J, Craig D, et al. Statins for the treatment of dementia. Cochrane Database Syst Rev 2010; 4:CD007514.

43. Whitmer RA, Karter AJ, Yaffe K, Quesenberry CP, Selby JV. Hypoglicemic episodes and risk of dementia in older patients with type 2 diabetes mellitus. JAMA 2009;301:1565-1572.

44. Williamson JD, Miller ME, Bryan RN, et al. The action to control cardiovascular risk in diabetes memory in diabetes study (ACCORD-MIND): rationale, design, and methods. Am J Cardiol 2007;99:S112-S122.

45. Bonds DE, Miller ME, Bergenstal RM, et al. The association between symptomatic, severe hypoglycaemia and mortality in type 2 diabetes: retrospective epidemiological analysis of the ACCORD study. BMJ 2010;340:b4909.

46. Jefferson AL, Himali JJ, Beiser AS, et al. Cardiac Index is associated with brain aging. The Framingham Heart Study. Circulation 2010;122:690-697.

47. Massaro AR, Dutra AP, Almeida DR, Diniz RV, Malheiros SM. Transcranial Doppler assessment of cerebral blood flow: effect of cardiac transplantation. Neurology 2006;66:124-126.

48. Jefferson AL, Tate DF, Poppas A, et al. Lower cardiac output 
is associated with greater white matter hyperintensities in older adults with cardiovascular disease. J Am Geriatr Soc 2007;55:1044-1048.

49. Paulson OB, Jarden JO, Godtfredsen J, Vorstrup S. Cerebral blood flow in patients with congestive heart failure treated with captopril. Am J Med 1984;76:91-95.

50. Rajagopalan B, Raine AEG, Cooper R, Ledingham JGG. Changes in cerebral blood flow in patients with severe congestive cardiac failure before and after captopril treatment. Am J Med 1984;76:86-90.

51. Zuccala G, Onder G, Marzetti E, et al. Use of angiotensinconverting enzyme inhibitors and variations in cognitive performance among patients with heart failure. Eur Heart J 2005;26:226-233.

52. Hajjar I, Hart M, Milberg W, Novak V, Lipsitz L. The rationale and design of the antihypertensives and vascular, endothelial, and cognitive function (AVEC) trial in elderly hypertensives with early cognitive impairment: role of the rennin angiotensin system inhibition. BMC 2009;9:48.

53. Kwok CS, Loke YK, Hale R, Potter JF, Myint PK. Atrial fibrillation and incidence of dementia: a systematic review and metaanalysis. Neurology 2011;76:914-922.

54. Flaker GC, Pogue J, Yusuf S, et al. Cogntive function and anticoagulation control in patients with atrial fibrillation.Circ Cardiovasc Qual Outcomes 2010;3:277.

55. Elwood PC, Bayer AJ, Fish M, et al. Sleep disturbance and daytime sleepiness predict vascular dementia. J Epidemiol Community Health 2010;epub ahead of print.

56. Ancoli-Israel S, Palmer BW, Cooke JR, et al. Cognitive effects of treating obstructive sleep apnea in Alzheimer's disease: a randomized controlled study. J Am Geriatr Soc 2008; 56:2076-2081.

57. Anstey KJ, von Sanden C, Salim A, O’Kearney R. Smoking as a risk factor for dementia and cognitive decline: a meta-analysis of prospective studies. Am J Epidemiol 2007;166: 367-378.

58. Ferri CP, West R, Moriyama TS, et al. Tobacco use and dementia: evidence from 1066 dementia population-based surveys in Latin America, China and India. Int J Geriatr Psychiatry 2011;doi: 10.1002/gps.2661, Epub ahead of print.

59. Rusanen M, Kivipelto M, Quesenberry CP Jr, Zhou J, Whitmer RA. Heavy smoking in midlife and long-term risk of Alzheimer and vascular dementia. Arch Intern Med 2011; 171:333-339.

60. AD2000 Collaborative Group. Aspirin in Alzheimer's disease (AD2000): a randomized open-label trial. Lancet Neurol 2008;7:41-49.

61. Thoonsen H, Richard E, Bentham P, et al. Aspirin in Alzheimer's disease. Increased risks of intracerebral hemorrhage: cause for concern? Stroke 2010;41:2690

62. Szekely CA, Breitner JC, Fitzpatrick AL, et al. NSAID use and dementia risk in the Cardiovascular Health Study: role of APOE and NSAID type. Neurology 2008;70:17-24.

63. Waldstein SR, Wendell CR, Seliger SL, Ferrucci L, Metter EJ, Zonderman AB. Nonsteroidal anti-inflammatory drugs, aspirin, and cognitive function in the Baltimore longitudinal study of aging. J Am Geriatr Soc 2010;58:38-43.

64. Price JF, Stewart MC, Deary IJ, et al. Low dose aspirin and cognitive function in middle aged to elderly adults: randomized controlled trial. BMJ 2008;337:a1198.
65. Diener H-C, Sacco RL, Yusuf S, et al. Effects of aspirin plus extended-release dipyridamole versus clopidogrel and telmisartan on disability and cognitive function after recurrent stroke in patients with ischaemic stroke in the Prevention Regimen for Effectively Avoiding Second Strokes (PRoFESS) trial: a double-blind, active and placebo-controlled study. Lancet Neurol 2008;7:875-884.

66. Bo M, Massaia M, Speme $S$, et al. Risk of cognitive decline in older patients after carotid endarterectomy: an observational study. J Am Geriatr Soc 2006;54:932-936.

67. Crawley F, Stygall J, Lunn S, Harrison M, Brown MM, Newman S. Comparison of microembolism detected by transcranial Doppler and neuropsychological sequelae of carotid surgery and percutaneous transluminal angioplasty. Stroke 2000;31:1329-1334.

68. Grunwald IQ, Supprian T, Politi M, et al. Cognitive changes after carotid artery stenting. Neuroradiology 2006;48:319-323.

69. Kishikawa K, Kamouchi M, Okada Y, et al. Effects of carotid endarterectomy on cerebral blood flow and neuropsychological test performance in patients with high-grade carotid stenosis. J Neurol Sci 2003;213:19-24.

70. Lunn S, Crawley F, Harrison MJG, Brown MM, Newman SP. Impact of carotid endarterectomy upon cognitive functioning. a systematic review of the literature. Cerebrovasc Dis 1999;9:74-81.

71. Rao R. The role of carotid stenosis in vascular cognitive impairment. Eur Neurol 2001;46:63-69.

72. Rango P, Caso V, Didier L, et al. The role of carotid artery stenting and carotid endarterectomy in cognitive performance: a systematic review. Stroke 2008;39:3116-3127.

73. Sivaguru A, Gaines PA, Beard J, Venables GS. Neuropsychological outcome after carotid angioplasty: a randomized control trial (Abstract). J Neurol Neurosurg Psychiatry 1999;66: 262.

74. Witt K, Borsch K, Daniels C, et al. Neuropsychological consequences of endarterectomy and endovascular angioplasty with stent placement for treatment of symptomatic carotid stenosis. A prospective randomized study. J Neurol 2007, 254:1524-1532.

75. Xu G, Liu X, Meyer JS, Yin Q, Zhang R. Cognitive performance after carotid angioplasty and stenting with brain protection devices. Neurol Res 2007;29:251-255.

76. Birks J, Grimley EJ. Ginkgo biloba for cognitive impairment and dementia. Cochrane Database of Systematic Reviews 2011 In: The Cochrane Library, Issue 03, Art. No. CD003120. DOI: 10.1002/14651858.CD003120.pub4.

77. Fioravanti M, Flicker L. Nicergoline for dementia and other age associated forms of cognitive impairment. Cochrane Database of Systematic Reviews 2011. In: The Cochrane Library, Issue 03, Art. No. CD003159. DOI: 10.1002/14651858.CD003159.pub4.

78. Szatmári S, Whitehouse P. Vinpocetine for cognitive impairment and dementia. Cochrane Database of Systematic Reviews 2011. In: The Cochrane Library, Issue 03, Art. No. CD003119. DOI: 10.1002/14651858.CD003119.pub4.

79. Schneider L, Olin JT, Novit A, Luczak S. Hydergine for dementia. Cochrane Database of Systematic Reviews 2011. In: The Cochrane Library, Issue 03, Art. No. CD000359. DOI: 10.1002/14651858.CD000359.pub4.

80. Flicker L, Grimley EJ. Piracetam for dementia or cognitive impairment. Cochrane Database of Systematic Reviews 2011. In: The Cochrane Library, Issue 03, Art. No. CD001011. DOI: 10.1002/14651858.CD001011.pub4. 
81. Sha MC, Callahan CM. The efficacy of pentoxifylline in the treatment of vascular dementia: a systematic review. Alz Dis Ass Disord 2003;17:46-54.

82. Fioravanti M, Yanagi M. Cytidinephosphocholine (CDP-choline) for cognitive and behavioural disturbances associated with chronic cerebral disorders in the elderly. Cochrane Database of Systematic Reviews 2011. In: The Cochrane Library, Issue 03, Art. No. CD000269. DOI: 10.1002/14651858.CD000269.pub4.

83. Guekht AB, Moessler H, Novak PH, Gusev EI; on behalf of the Cerebrolysin Investigators. Cerebrolysin in vascular dementia: improvement of clinical outcome in a randomized, doubleblind, placebo-controlled multicenter trial. J Stroke Cerebrovasc Dis 2010 doi:10.1016/j.jstrokecerebrovasdis.2010.01.012.

84. Kavirajan H, Schneider LS. Efficacy and adverse effects of cholinesterase inhibitors and memantine in vascular dementia: a meta-analysis of randomised controlled trials. Lancet Neurol 2007;6:782-792.

85. Black S, Roman G, Geldmacher D, et al. Efficacy and tolerability of donepezil in vascular dementia positive results of a 24 -week multicenter internationl randomized placebo controlled trial. Stroke 2003;43:2323-2332.

86. Pratt RD, Perdomo CA. Donepezil-treated patients with probable vascular dementia demonstrate cognitive benefits. Ann NY Acad Sci 2002;977:513-522.

87. Salloway SP, Pratt RD, Perdomo CA. Donepezil is well tolerated in patients with vascular dementia: a comparison of tolerability in vascular dementia patients and Alzheimer's disease patients. Eur J Neurol 2002;9:165-224.

88. Wilkinson D, Doody R, Helme R, Taubman K, Mintzer J, Kertesz A, Pratt RD. Donepezil in vascular dementia a randomized placebo controlled study. Neurology 2003;61:479-486.

89. Meyer JS, Chowdhury MH, Xu G, Li YS, Quach M. Donepezil treatment of vascular dementia. Ann NY Acad Sci 2002;977:482-486.

90. Erkinjuntti T, Skoog I, Lane R, Andrews C. Potential long term effects of rivastigmine on disease progression may be linked to drug effects on vascular changes in Alzheimer's disease. International J Clin Pract 2003;57:756-760.

91. Kumar V, Anand R, Messina J, Hartman R, Veach J. An efficacy and safety analysis of Exelon in Alzheimer's disease patients with concurrent vascular risk factors. Eur J Neurol 2000;7:159-169.

92. Moretti R, Torre P, Antonello RM, Cazzato G. Rivastigmine in subcortical vascular dementia: a comparison trial on efficacy and tolerability for 12 months follow up. Eur J Neurol 2001;8: 361-362.

93. Moretti R, Torre P, Antonello RM, Cazzato G, Bava A. Rivastigmine in subcortical vascular dementia: an open 22-month study. J Neurol Sci 2002;15:141-146.
94. Moretti R, Torre P, Antonello RM, Cazzato G, Bava A. Rivastigmine in subcortical vascular dementia: A randomized, controlled, open 12-month study in 208 patients. Am J Alzh Dis Other Dementias 18:265-272.

95. Bullock R, Erkinjuntti T, Lilienfeld S. Management of patients with Alzheimer's disease plus cerebrovascular disease: 12-month treatment with galantamine. Dem Geriatr Cogn Dis 2004;17:29-34.

96. Erkinjuntti T, Kurz A, Gauthier S, Bullock R, Lilienfeld S, Damaraju CV. Efficacy of galantamine in probable vascular dementia and Alzheimer's disease combined with cerebrovascular disease: a randomised trial. Lancet 2002;359:1283-1290.

97. Erkinjuntti T, Kurz A, Small GW, Bullock R, Lilienfeld S, Damaraju CV. An open-label extension trial of galantamine in patients with probable vascular dementia and mixed dementia. Clin Therap 2003;25:1765-1782.

98. Kertesz A. Efficacy of galantamine in probable vascular dementia and Alzheimer's disease combined with cerebrovascular disease: a randomized trial. Curr Neurol Neurosc Rep 2002;2:503-504.

99. Kurz AF, Erkinjuntti T, Small GW, Lilienfeld S, Damaraju CR. Long-term safety and cognitive effects of galantamine in the treatment of probable vascular dementia or Alzheimer's disease with cerebrovascular disease. Eur J Neurol 2003;10:633-640.

100. Small G, Erkinjuntti T, Kurz A, Lilienfeld S. Galantamine in the treatment of cognitive decline in patients with vascular dementia or Alzheimer's disease with cerebrovascular disease. CNS drugs 2003;17:905-914.

101. McShane R, Areosa AS, Minakaran N. Memantine for dementia. Cochrane Database of Systematic Reviews 2011. In: The Cochrane Library, Issue 03, Art. No. CD003154. DOI: 10.1002/14651858.CD003154.pub1.

102. Möbius HJ. Memantine: update on the current evidence. Int J Geriatr Psychiatr 2003;18:S47-S54.

103. Pantoni L, del Ser T, Soglian AG, et al. Efficacy and safety of nimodipine in subcortical vascular dementia. A randomized placebo-controlled trial. Stroke 2005;36:619-624.

104. Birks J, López-Arrieta J. Nimodipine for primary degenerative, mixed and vascular dementia. Cochrane Database of Systematic Reviews 2011. In: The Cochrane Library, Issue 03, Art. No. CD000147. DOI: 10.1002/14651858.CD000147.pub4.

105. Spanish Group of Nicardipine Study in Vascular Dementia. An experimental, randomized, double-blind, placebo-controlled clinical trial to investigate the effect of nicardipine on cognitive function in patients with vascular dementia. Rev Neurol 1999;15:835-845.

106. Gonzalez-Gonzalez JA, Lozano RA. Study of the tolerability and effectiveness of nicardipine retard in cognitive deterioration of vascular origin. Rev Neurol 2000;30:719-728 


\section{GROUP RECOMMENDATIONS IN ALZHEIMER'S DISEASE AND VASCULAR DEMENTIA OF THE BRAZILIAN ACADEMY OF NEUROLOGY}

Amauri B. da Silva [UnINEURO, Recife (PE)]; Analuiza Camozzato de Pádua [Universidade Federal de Ciências da Saúde de Porto Alegre (UFCSPA); Hospital de Clínicas de Porto Alegre (UFRGS) (RS)]; Antonio Lúcio Teixeira [Departamento de Clínica Médica, Faculdade de Medicina da Universidade Federal de Minas Gerais, Belo Horizonte (MG)]; Benito Pereira Damasceno [Departamento de Neurologia da Universidade Estadual de Campinas (SP)]; Carla Tocquer [Universidade Federal do Rio de Janeiro (RJ)]; Carlos Alberto Buchpiguel [Departamento de Radiologia, Faculdade de Medicina da Universidade de São Paulo (SP)]; Cássio Machado C. Bottino [Programa Terceira Idade, Instituto de Psiquiatria do Hospital das Clínicas da Faculdade de Medicina da Universidade de São Paulo (FMUSP) (SP)]; Charles André [Faculdade de Medicina - UFRJ; SINAPSE Reabilitação e Neurofisiologia (RJ)]; Cláudia C. Godinho [Serviço de Neurologia do Hospital de Clínicas de Porto Alegre, Universidade Federal do Rio Grande do Sul (RS)]; Cláudia Sellitto Porto [Grupo de Neurologia Cognitiva e do Comportamento da Faculdade de Medicina da USP (SP)]; Delson José da Silva [Núcleo de Neurociências do Hospital das Clínicas da Universidade Federal de Goiás (UFG); Instituto Integrado de Neurociências (IINEURO), Goiânia (GO)]; Denise Madeira Moreira [Departamento de Radiologia Faculdade de Medicina - UFRJ; Setor de Radiologia - IN DC - UFRJ (RJ)]; Eliasz Engelhardt [Setor de Neurologia Cognitiva e do Comportamento - IN DC - CDA/IPUB - UFRJ (RJ)]; Elza Dias-Tosta [Presidente da Academia Brasileira de Neurologia, Hospital de Base do Distrito Federal (DF)]; Emílio Herrera Junior [Departamento de Medicina Interna, Faculdade de Medicina de Catanduva (SP)]; Francisco de Assis Carvalho do Vale [Universidade Federal de São Carlos (UFSCar), Departamento de Medicina (DMed) (SP)]; Hae Won Lee [Instituto de Radiologia, Hospital das Clínicas da Faculdade de Medicina da Universidade de São Paulo e Hospital SírioLibanês (SP)]; Ivan Hideyo Okamoto [Departamento de Neurologia e Neurocirurgia; Instituto da Memória - Universidade Federal de São Paulo - UNIFESP (SP)]; Jerusa Smid [Grupo de Neurologia Cognitiva e do Comportamento do Hospital das Clínicas da Faculdade de Medicina da Universidade de São Paulo (FMUSP) (SP)]; João Carlos Barbosa Machado [Aurus IEPE - Instituto de Ensino e Pesquisa do Envelhecimento de Belo Horizonte; Faculdade de Ciências Médicas de Minas Gerais (FCMMG), Serviço de Medicina Geriátrica do Hospital Mater Dei (MG)]; José Antonio Livramento [Laboratório de Investigação Médica (LIM) 15, Faculdade de Medicina da Universidade de São Paulo (SP)]; Jose Luiz de Sá Cavalcanti [Departamento de Neurologia - INDC - UFRJ; Setor de Neurologia Cognitiva e do Comporta $\neg$ mento - INDC - UFRJ (RJ)]; Letícia Lessa Mansur [Grupo de Neurologia Cognitiva e do Comportamento do Departamento de Neurologia da FMUSP;
Departamento de Fisioterapia, Fonoaudiologia e Terapia Ocupacional da Faculdade de Medicina da USP (SP)]; Márcia Lorena Fagundes Chaves [Serviço de Neurologia do Hospital de Clínicas de Porto Alegre, Universidade Federal do Rio Grande do Sul (RS)]; Márcio Luiz Figueredo Balthazar [Universidade Estadual de Campinas (UNICAMP), Faculdade de Ciências Médicas (FCM), Departamento de Neurologia (SP)]; Maria Teresa Carthery-Goulart [Grupo de Neurologia Cognitiva e do Comportamento do Departamento de Neurologia da Faculdade de Medicina da USP; Centro de Matemática, Computação e Cognição, Universidade Federal do ABC (SP)]; Mônica S. Yassuda [Grupo de Neurologia Cognitiva e do Comportamento do Departamento de Neurologia da Faculdade de Medicina da USP; Departamento de Gerontologia, Escola de Artes, Ciências e Humanidades da USP (EACH/USP Leste) (SP)]; Nasser Allam [Universidade de Brasília (UnB), Laboratório de Neurociências e Comportamento, Brasília (DF)]; Norberto Anizio Ferreira Frota [Universidade de Fortaleza (UNIFOR), Serviço de Neurologia do Hospital Geral de Fortaleza (HGF) (CE)]; Orestes Forlenza [Laboratório de Neurociências - LIM27, Departamento e Instituto de Psiquiatria da Faculdade de Medicina da Universidade de São Paulo (FMUSP) (SP)]; Paulo Caramelli [Departamento de Clínica Médica, Faculdade de Medicina da Universidade Federal de Minas Gerais, Belo Horizonte (MG)]; Paulo Henrique Ferreira Bertolucci [Universidade Federal de São Paulo (UNIFESP), Setor de Neurologia do Comportamento - Escola Paulista de Medicina, São Paulo (SP)]; Regina Miksian Magaldi [Serviço de Geriatria do Hospital das Clínicas da FMUSP, Centro de Referencia em Distúrbios Cognitivos (CEREDIC) da FMUSP (SP)]; Renata Areza-Fegyveres [Grupo de Neurologia Cognitiva e do Comportamento do Hospital das Clínicas da Faculdade de Medicina da Universidade de São Paulo (FMUSP) (SP)]; Renato Anghinah [Grupo de Neurologia Cognitiva e do Comportamento do Hospital das Clínicas da Faculdade de Medicina da Universidade de São Paulo (FMUSP); Centro de Referência em Distúrbios Cognitivos (CEREDIC) da FMUSP (SP)]; Ricardo Nitrini [Grupo de Neurologia Cognitiva e do Comportamento do Hospital das Clínicas da Faculdade de Medicina da Universidade de São Paulo (FMUSP); Centro de Referência em Distúrbios Cognitivos (CEREDIC) da FMUSP (SP)]; Rogério Beato [Grupo de Pesquisa em Neurologia Cognitiva e do Comportamento, Departamento de Medicina Interna, Faculdade de Medicina, UFMG (MG)]; Tânia Novaretti [Faculdade de Filosofia e Ciências, Campus de Marília, da Universidade Estadual Paulista (UNESP) (SP)]; Valéria Santoro Bahia [Grupo de Neurologia Cognitiva e do Comportamento do Hospital das Clínicas da Faculdade de Medicina da Universidade de São Paulo (FMUSP) (SP)]; Ylmar Corrêa Neto [Universidade Federal de Santa Catarina (UFSC), Departamento de Clínica Médica, Florianópolis (SC)]. 